\title{
Mortality among retired offshore divers in Norway
}

\author{
Ågot Irgens ${ }^{1,2}$, Rune Djurhuus ${ }^{1,2,3}$, Marit Grønning ${ }^{1,2,4}$ \\ ${ }^{1}$ Norwegian Centre for Diving Medicine, Department of Occupational Medicine, \\ Haukeland University Hospital, Bergen, Norway \\ ${ }^{2}$ Department of Occupational Medicine, \\ Haukeland University Hospital, Bergen, Norway \\ ${ }^{3}$ Norwegian Centre for Maritime Medicine, Department of Occupational Medicine, \\ Haukeland University Hospital, Bergen, Norway \\ ${ }^{4}$ Department of Clinical Medicine (K1), University of Bergen, Norway
}

\begin{abstract}
Background: Health effects of diving have been observed in divers who have not experienced any diving related accidents. The aim of the study was to study total, and cause specific mortality, in Norwegian retired professional offshore divers.

Materials and methods: We carried out a mortality follow-up from 1997 to 2013 in a group of men, born 1930-1973. The diving cohort consisted of 386 male professional divers diving in the North Sea in the pioneer period from 1965 to 1990, of which 25 were dead. 1,467,769 Norwegian males were used as referents. This population was linked to the Norwegian Cause of Death Registry.

Results: Twenty five (6.5\%) professional offshore divers had died. No differences were observed between divers and referents for overall mortality or for non-violent deaths, adjusted for year of birth.

Conclusions: In this cohort of retired North Sea divers, the mortality pattern did not differ from that of the expected mortality.
\end{abstract}

(Int Marit Health 2015; 66, 2: 93-96)

\section{Key words: mortality, non-violent death, registry, professional diving, offshore}

\section{INTRODUCTION}

Apart from the immediate risks associated with the technical and operational procedures including decompression procedures, diving is associated with exposure to hyperoxia, high ambient pressure and increased gas density. Diving may have both immediate and long-term effects on the lungs [1], the central nervous system [2], bone [3, 4] and the audio-vestibular system [5]. Furthermore exposure to life threatening events may cause serious psychological distress [6]. Several of these factors might affect the retired divers' health and mortality; a group in which a supreme health has been required [7] to obtain certificate for occupational diving.

Mortality in divers has most often been presented as case studies or reports on technical and environmental conditions in accidents with fatal outcome [8-11].

In 2013 we studied mortality in Norwegian male inshore divers in comparison to male referents from the Norwegian population [12]. This study demonstrated a reduced overall mortality in active and retired divers with class I certificate (Health and Safety Executive part 1 equivalent), professional male inshore divers with higher certificates (class II [closed bell] or III [standard gear]) had, however, a higher risk of dying from accidents and suicide [12].

A commission appointed by the Norwegian government in 2001 reported an increased occurrence of suicides among North Sea divers [13]. However, the allegation is difficult to verify since it is based on non-scientific sources and undocumented cases.

To the best of our knowledge no studies have described the mortality of professional offshore divers after they have finished their diving career. In this paper we will address this question, and we will compare the results to our previous study of professional male inshore divers [12].

Ågot Irgens, MSc, Norwegian Centre for Diving Medicine, Department of Occupational Medicine, Haukeland University Hospital, 5021 Bergen, Norway, tel: +4755973882, e-mail: agot.irgens@helse-bergen.no 


\section{MATERIALS AND METHODS}

\section{SUBJECTS}

Petroleum Safety Authority Norway has operated the Norwegian Offshore Diver Registry compulsory on all divers ever holding a certificate valid for offshore diving. Even so, the actual number of Norwegian offshore divers employed in the North Sea in the pioneer period 1965-1990, has been a matter of discussion.

Pursuant to a decision by the Parliament on 13 June 2000, the Norwegian government appointed on 2 March 2001 an independent Commission of Enquiry to investigate all circumstances related to diving in the North Sea in the pioneer period. The Commission's report, "Pioneer divers in the North Sea", from 2002 [13] included around 350 male North Sea divers. From the commission we received a list of 360 divers of whom 3 were already dead before their investigation and 6 were living abroad. These remaining 351 and 37 additional pioneer offshore divers who were traced by the North Sea diver Survey at Haukeland University Hospital [14], were included in the present study.

The cohort of all members of retired North Sea divers, all male, was identified by the national identification number. This enabled us through the National Population Registry to investigate who were still alive in 2013. Twenty six (6.7\%) of the 388 divers had died since 1997.

The Regional Committee for Medical and Health Research Ethics approved this study, but recommended a passive informed consent, requiring that all divers still alive had to be informed about the study. One diver refused to participate and was excluded, leaving 387 in the diver cohort.

Based on compulsory notification, all deaths in Norway have to be reported to The Norwegian Cause of Death Registry (death registry) [15] by the medical doctor who fills in the death certificate. All causes of death in this study have been coded according to the International Classification of Diseases version 10 (ICD-10) [16].

By the national identification number, all male divers were linked to the Cause of Death Registry. Death diagnoses, year of birth and year of death were available for 25 of the 26 deceased divers and referents ( $n=125,901)$. One of these divers had died abroad, and since both year and cause of death was missing in the death registry, he was excluded from the study. All subjects included in the study were born 1930-1973 and were alive in 1997.

Data on the total male population born 1930-1973 were collected from Statistics Norway [17]. The study thus included 386 male divers and 1,467,769 male referents.

The primary cause of death was recoded according to The European Causes of Death short list [16]. Due to the small diving cohort we focused on the categories: overall mortality, non-violent deaths (ICD-10 A-R96) and violent deaths (ICD-10 V-Y09), including suicides (intentional selfharm ICD-10 X60-X84). In addition the occurrence of ill-defined and unknown causes of mortality (ICD-10 R95-R99) was analysed.

\section{STATISTICAL METHOD}

The crude relative risks of overall and cause-specific mortality were calculated by logistic regression. Survival times were included in the analysis of overall mortality and non-violent deaths, and hazard ratios, crude and adjusted for year of birth, were calculated by Cox regression analysis. The year of censoring was set to 2013.

All statistical analyses were performed by IBM, SPSS Statistics version 22 [18].

\section{RESULTS}

Twenty-five (6.5\%) deaths were observed among retired male North Sea divers against 125,901 (8.6\%) in the referent population.

The numbers of cause-specific deaths, mean age at death with standard deviation, are presented for divers and referents in Table 1.

In the cohort of retired male offshore divers no deviating risks were observed for any of the cause of death specific categories (Table 2). According to the European short list 2 deaths were classified as suicide (self-intentional harm). The prevalence of ill-defined or unknown causes of death was higher among divers than referents.

\section{DISCUSSION}

In this study of retired North Sea divers, no differences in mortality could be detected between divers and referents. Classified from 'The European Causes of Death short list' $2(0.5 \%)$ cases were suicide among divers and $0.3 \%$ among referents. The prevalence of ill-defined causes of death or unknown deaths was higher among divers.

Both in this and in our previous mortality study of male inshore divers [12], all data had been collected beforehand by Norwegian authorities. Consequently, selection bias was reduced. The national identification number enabled linkage of divers to the death registry. Based on data from the death registry, we could compare divers to other Norwegian men born in the same period. There are, however, some caveats. It should be emphasized that due to low numbers in the diver cohort the statistical power is low. In addition we had no information on occupational diving exposure like number of dives or the length of their diving career. The reference population of men at the same age as the offshore divers will include both recreational and inshore divers. Thus, pressure, hyperoxia, increased gas density etc. were not hazards absolutely unique to the identified diver population. This fact could underestimate effects 
Table 1. Cause-specific mortality among retired male divers and referents (1997-2013) and mean age at death\#

\begin{tabular}{|c|c|c|c|c|}
\hline & \multicolumn{2}{|c|}{ Divers } & \multicolumn{2}{|l|}{ Referents } \\
\hline & $\mathbf{N}$ & Age mean \pm SD & $\mathbf{N}$ & Age mean \pm SD \\
\hline Deceased & 25 & $61.2 \pm 5.8$ & 125,901 & $64.2 \pm 11.3$ \\
\hline Non-violent death & 22 & $61.9 \pm 5.7$ & 114,146 & $65.4 \pm 10.4$ \\
\hline III-defined/unknown & 3 & $64.7 \pm 4.2$ & 3,293 & $63.0 \pm 10.7$ \\
\hline Violent death & 3 & $55.7 \pm 3.2$ & 11,755 & $52.3 \pm 13.3$ \\
\hline Suicide & 2 & $54.5 \pm 3.5$ & 4,036 & $50.0 \pm 12.4$ \\
\hline Surviving* & 361 & $60.9 \pm 6.5$ & $1,341,868$ & $56.8 \pm 11.3$ \\
\hline
\end{tabular}

\#All were still alive in 1997; *Mean age in 2013; SD - standard deviation

Table 2. Mortality and risks of cause-specific death in retired male divers and referents ${ }^{\#}$

\begin{tabular}{lllllllll}
\hline & Divers & Referents & $\begin{array}{l}\text { Crude } \\
\text { OR* }\end{array}$ & 95\% Cl & $\begin{array}{l}\text { Crude } \\
\text { HR** }\end{array}$ & 95\% Cl & HR*** 95\% Cl \\
\hline Overall mortality & $25(6.5 \%)$ & $125,901(8.6 \%)$ & 0.73 & $0.49-1.11$ & 0.92 & $0.63-1.37$ & 0.81 & $0.54-1.19$ \\
Non-violent death & $22(5.7 \%)$ & $114,146(7.8 \%)$ & 0.72 & $0.47-1.10$ & 0.93 & $0.61-1.41$ & 0.81 & $0.53-1.23$ \\
$\quad$ III-defined/unknown & $3(0.8 \%)$ & $3,293(0.2 \%)$ & 3.48 & $1.12-10.9$ & & & & \\
Violent death & $3(0.8 \%)$ & $11,755(0.8 \%)$ & 0.97 & $0.31-3.02$ & & & & \\
$\quad$ Suicide & $2(0.5 \%)$ & $4,036(0.3 \%)$ & 1.89 & $0.47-7.58$ & & & &
\end{tabular}

\#All were still alive in 1997; *Crude odds ratio (OR) from logistic regression; $* *$ Crude hazard ratio (HR) from Cox regression analysis; ***Hazard ratio adjusted for year of birth; $\mathrm{Cl}$ - confidence interval

of diving, but considering the size of the reference group, problems due to misclassification of divers as referents should be negligible. The quality of the cause of death registries in Scandinavia has been under debate [19, 20]. A Norwegian diabetes study [21] presented causes of death codes together with all available data on each case for a clinical review committee. Fifty three of 103 deaths were reclassified with respect to cause of death, including 7 cases that were changed from accident to suicide, illustrating a considerable lack of consistency or uncertainty in classification of cause of death. Accordingly, the classification of causes of deaths in the cohort in the present study may therefore be uncertain, but there is no reason to believe that this uncertainty or possible misclassification is different from that of the reference group.

The aim of this study was to study mortality, and suicides, in offshore divers after retirement. High suicide rates among fellow workers are rumoured by retired offshore divers. Also the Commission's report from 2002 [13] concluded that the number of suicides had been very high among these divers with a frequency of $3 \%$, although the actual numbers are uncertain. In contrast only 2 cases of suicide were observed in the cohort of retired offshore divers in the present study, resulting in a frequency of $0.5 \%$ suicides. That is comparable to a frequency of $0.6 \%$ suicides observed among 2,111 divers in a previous British study [11]. It should be noted that both the report from the Commission
[13] and the British study include both active and retired divers, while the present study comprises retired divers only.

The occurrence of ill-defined causes of death and undefined deaths was significantly higher among divers. According to the death registry this diagnosis will mostly appear in deaths abroad, where further investigation of cause of death is difficult. On the correct cause of death one can only speculate. Misclassification of suicides as accidents may often be questioned.

Data from the Petroleum Safety Authority statistics [22] shows that the mortality and accidents among active offshore divers in the offshore industry today are considerably reduced, as compared to the situation in the pioneer period in the 1970s and 1980s.

\section{CONCLUSIONS}

In this cohort of retired North Sea divers, the mortality pattern did not differ from that of the expected mortality.

\section{ACKNOWLEDGEMENTS}

We are most grateful to Berit Johannessen at the Department of Occupational Medicine who identified the deceased divers.

\section{FUNDING}

This work was supported by The Norwegian Centre for Diving Medicine. 


\section{CONFLICT OF INTEREST}

The authors declare no conflicts of interest.

\section{REFERENCES}

1. Thorsen E, Segadal K, Kambestad BK. Mechanisms of reduced pulmonary function after a saturation dive. Eur Respir J 1994; 7: 4-10.

2. Grønning M, Aarli JA. Neurological effects of deep diving. J Neurol Sci 2011; 304: 17-21. doi: 10.1016/j.jns.2011.01.021.

3. Jiang CQ, Wang B, Yu CF et al. Dysbaric osteonecrosis by X-ray and CT scan in Chinese divers. Undersea Hyperb Med 2005; 32: 169-174.

4. Uzun G, Toklu AS, Yildiz S et al. Dysbaric osteonecrosis screening in Turkish Navy divers. Aviat Space Environ Med 2008; 79: 44-46.

5. Goplen FK, Grønning M, Irgens A, Sundal E, Nordahl SH. Vestibular symptoms and otoneurological findings in retired offshore divers. Aviat Space Environ Med 2007; 78: 414-419.

6. Troland K, Sundal E, Irgens A, Gronning M, Thorsen E. Potentially traumatic events and posttraumatic stress reaction in retired North Sea divers. Proceedings of the XXVIIth annual meeting of the European Underwater Biomedical Society (EUBS). Gdansk, Poland: EUBS, 2011: 22. Available from: http://www.daneurope. org/c/document_library/get_file?uuid=c57ead31-16fe-4d8f-88bc-a302540ef22b\&groupld=10103 (May 2015, date last accessed).

7. Regulations regarding health requirements for offshore divers in Norway. The county governor in Rogaland. Available from: http:// www.fylkesmannen.no/Documents/Dokument\%20FMRO/Helse $\% 20$ og\%20sosial/Regelverk\%20og\%20styringsdokument/Helsekravforskriften\%20engelsk\%202011.pdf (May 2015, date last accessed).

8. Bradley ME. Commercial diving fatalities. Aviat Space Environ Med 1984; 55: 721-724.

9. Denoble PJ, Caruso JL, Dear Gde L, Pieper CF, Vann RD. Common causes of open-circuit recreational diving fatalities. Undersea Hyperb Med 2008; 35: 393-406.

10. Lippmann J, Lawrence C. Diving-related deaths in Hong Kong waters, 2006-2009. Undersea Hyperb Med 2012; 39: 891-900.

11. McCallum RI. A study of the mortality of professional divers. In: Hope A, Lund T, Elliot DG, Halsey MJ, Wiig H eds. Long term health effects of diving (1993). Proceedings of International Consensus
Conference. Godoysund; Bergen: Norwegian Underwater Technology Centre as 1993; pp. 179-185.

12. Irgens $\AA$, Troland K, Thorsen E, Grønning M. Mortality among professional divers in Norway. Occup Med (Lond) 2013; 63: 537-543. doi: $10.1093 /$ occmed/kqt112.

13. Pionerdykkerne i Nordsjøen [The pioneer divers in the North Sea]. Oslo: Ministry of Government Administration, Reform and Church Affairs, NOU 2003:5 [Commission of Enquiry to investigate all circumstances related to diving in the North Sea in the pioneer period.]. Available from: https://www.regjeringen.no/nb/dokumenter/nou2003-5/id381525/ (May 2015, date last accessed).

14. Sundal E, Irgens Å, Troland K, Thorsen E, Grønning M. Prevalence and causes of loss of consciousness in former North Sea occupational divers. Int Marit Health 2013; 64: 142-147.

15. Dødsårsaksregisteret [The Cause of death Registry of Norway]. Available from: http://www.fhi.no/helseregistre/dodsaarsaksregisteret (May 2015, date last accessed).

16. The Codebook from the Cause of Death registry. European short-list for causes of death, 3-5. Available from: http://www.fhi.no/dokumenter/1ae6a6cbc0.pdf (May 2015, date last accessed).

17. Statistisk Årbok 2013; 132: 67-68 [Statistics Norway]. Available from: http://www.ssb.no/befolkning/artikler-og-publikasjoner/_attachment/140702?_ts=143c3c6bff8 (May 2015, date last accessed).

18. IBM Corp. Released 2013. IBM SPSS Statistics for Windows, Version 22.0. Armonk, NY: IBM Corp.

19. Reseland S. [Bad quality of the Cause of Death Registry]. Tidsskr Nor Laegeforen 2009; 129: 894. doi: 10.4045/tidsskr.09.0392.

20. Gjersøe P, Andersen SE, Mølbak AG, Wulff HR, Thomsen 00. [Reliability of death certificates. The reproducibility of the recorded causes of death in patients admitted to departments of internal medicine]. Ugeskr Laeger 1998; 160: 5030-5034.

21. Skrivarhaug T, Bangstad HJ, Stene LC et al. Long-term mortality in a nationwide cohort of childhood-onset type 1 diabetic patients in Norway. Diabetologia 2006; 49: 298-305.

22. Petroleum Safety Authority statistics. Available from: http://www. ptil.no/?lang=en_US (May 2015, date last accessed). 